\title{
POSTER MENGATASI KECANDUAN GAME MOBILE TERHADAP GENERASI MASA KINI
}

\author{
Achmad Fauri $^{1)}$, Jevon Almadeo ${ }^{2)}$ \\ Program Studi Desain Komunikasi Visual \\ Fakultas Bahasa dan Seni, Universitas Indraprasta PGRI \\ J1. Nangka No. 58 C, Tanjung Barat, Jakarta Selatan, 12530, Indonesia \\ faurii29@gmail.com
}

\begin{abstract}
Abstrak
Tujuan perancangan poster mengatasi kecanduan game mobile terhadap generasi masa kini adalah sebagai media penyuluhan untuk para pemain serta penggunanya agar memperhatikan waktu mereka pada saat bermain. Dengan menggunakan metode kualitatif, yaitu melakukan tinjauan pustaka dengan cara mengumpulkan bahan-bahan materi yang bersumber dari buku, artikel dan beberapa jurnal online. Mobile game ternyata tidak hanya memiliki dampak negatif, tetapi juga terdapat dampak positif jika dimainkan dengan bijak dan dapat mengatur waktunya. Tulisan berdasar studi pustaka ini menguraikan dampak yang terjadi pada seseorang jika kecanduan mobile game, baik dari sisi negatif maupun sisi positif. Selain itu tulisan ini juga menguraikan himbauan untuk bermain dengan sehat dan juga bijak. Bagi yang tidak bisa menggunakannya dengan benar akan banyak sekali dampak negatif yang dapat didapat serta dirasakan. Seperti dari segi uang, waktu, semangat belajar, psikologi, kesehatan, dan juga hal sosial. Hal ini ditakutkan dapat menjadi semakin buruk di kemudian hari bila tidak ditangani.
\end{abstract}

Kata Kunci: Dampak, Mobile game, poster, kecanduan, generasi muda

\begin{abstract}
The purpose of designing posters to overcome the addiction of mobile games to the current generation is as a media counseling for the players and users to pay attention to their time while playing. By using a qualitative method, which is conducting a literature review by collecting material sourced from books, articles and some online journals. Mobile games have not only had a negative impact, but also a positive impact if played wisely and can manage the time. Posts based on this literature study describe the impact that can have on a person if addicted to mobile games, both from the negative and the positive sides. Besides this article also outlines the call to play healthy and also wise. Because for those who can't use it properly there will be a lot of negative impacts that can be obtained and felt. Like in terms of money, time, enthusiasm for learning, psychology, health, and also social matters. It is feared it could get worse in the future if left untreated.
\end{abstract}

Keywords: Impact, Mobile games, posters, addictions, the younger generation.

Correspondence author: Achmad Fauri, faurii29@gmail.com, Jakarta, and Indonesia

This work is licensed under a CC-BY-NC 


\section{PENDAHULUAN}

Teknologi pada era globalisasi saat ini sudah mengalami perkembangan yang cukup pesat dan juga cepat. Hal ini tentu saja secara tidak langsung memberikan pengaruh besar bagi sebagian kehidupan manusia salah satunya dalam aspek teknologi. Teknologi saat ini sepertinya sudah menjadi kebutuhan primer bagi manusia dengan didukung dengan berkembangnya ilmu pengetahuan yang cukup pesat dan cepat. Perkembangan teknologi pun juga mengalami perkembangan secara signifikan dan terus berkembang hingga saat ini dan sekarang hal tersebut semakin mendunia. Hal tersebut sudah dibuktikan dengan banyaknya tercipta inovasi dan penemuan yang baru pada zaman sekarang salah satunya ialah game mobile.

Game merupakan suatu kegiatan untuk menghibur diri sendiri dan juga menghilangkan rasa penat setelah melakukan berbagai aktivitas sehari-hari. Biasanya game dimainkan ketika waktu sedang kosong sehingga tidak akan mengganggu aktivitas lainnya. Untuk melakukan kegiatan ini biasanya memerlukan peralatan, misalnya sebuah papan permainan, komputer game, konsol, maupun handphone.

Game (permainan) merupakan salah satu dari hasil perkembangan teknologi. Permainan yang awalnya dimainkan di dunia nyata dengan berinteraksi dengan orang atau benda secara langsung, kini bisa dimainkan dalam bentuk digital menggunakan teknologi. Teknologi game saat ini pun telah meluas ke berbagai sektor pada kehidupan manusia sehari harinya.

Pada zaman sekarang pun telah berkembang sebuah permainan yang biasa disebut dengan game mobile. Game mobile ini sendiri pada zaman sekarang merupakan permainan yang menggunakan perangkat smartphone sebagai sarana ataupun media untuk bermain game. Sebuah game mobile pun dapat diperoleh dengan cukup mudah melalui aplikasi dan juga melalui internet. Berbagai teknologi game mobile saat ini nantinya pasti akan mengalami pertumbuhan yang drastis di masa depan nanti. Berbagai game dengan teknologi yang lebih canggih dan inovatif pun akan terus bermunculan. Hal ini pun secara tidak langsung berdampak sebagai salah satunya zaman sekarang bila dilihat sudah cukup jarang generasi sekarang yang bermain permainan permainan tradisional. Mereka semua lebih tertarik dan beralih pada game mobile di smartphone yang dirasa lebih praktis.

Namun bila diperhatikan game mobile tidak selalu memiliki dampak negatif. Ada cukup banyak dampak positif serta manfaatnya bagi para generasi muda masa kini, salah satunya yakni menghasilkan uang sendiri dengan bermain ataupun berjualan di dalam sebuah game mobile, bahkan ada beberapa yang dapat mengharumkan nama bangsanya dengan mengikuti kejuaraan game online mobile dengan membawa nama negaranya dan tidak luput juga dapat mengembangkan kemampuan komunikatif mereka dan learn to learn, karena bila dilihat saat ini mayoritas game mobile zaman sekarang sangat menuntut kerjasama yang komunikatif pada saat sedang bermain.

Perancangan poster ini bertujuan untuk menghasilkan desain dan bahasa yang tepat untuk masyarakat. Poster pun diharuskan untuk mampu menyampaikan sebuah informasi ataupun pesan kepada audiens hanya sekali lihat dan dalam hitungan detik. Hal ini mempertimbangkan waktu baca audiens yang begitu singkat dan dalam berbagai situasi yang sekiranya kurang memadai untuk berlama lama. Oleh karena itu, harus ditentukan pesan apa yang akan dijadikan elemen kunci yang akan disampaikan melalui poster tersebut.

Dalam perancangan poster kali ini, poster menyesuaikan dengan pesan yang ingin disampaikan, yaitu singkat, padat, menarik, dan mudah dimengerti oleh pembaca. Tujuan dari poster ini nantinya akan membentuk sikap atau pandangan para generasi muda masa kini bahwa game mobile dapat membuat kecanduan dan tidak baik bila dimainkan terlalu sering dapat mengganggu aktifitas sehari hari, sehingga membuka pikiran mereka. 


\section{METODE PENELITIAN}

Pada penelitian ini, peneliti menggunakan pendekatan kualitatif. Menurut Sugiyono (2010: 1), penelitian kualitatif merupakan penelitian yang digunakan untuk meneliti kondisi subjek yang alamiah

Pendekatan kualitatif kami gunakan untuk melakukan tinjauan pustaka dengan cara mengumpulkan bahan-bahan materi yang bersumber dari buku, artikel, dan beberapa jurnal online. Jenis data yang digunakan yaitu data kualitatif (berbentuk kata-kata/kalimat). Dari metode ini, barulah diperoleh data data berupa data sekunder.

Data sekunder yang kami gunakan dalam penelitian ini adalah artikel, jurnal ataupun melalui buku online. Lalu hasil dari kesimpulan yang telah didapat dari berbagai literatur ini kami digunakan untuk memberikan solusi desain bagi permasalahan mengatasi kecanduan game mobile pada generasi masa kini,

\section{HASIL DAN PEMBAHASAN}

\section{Game}

Kemajuan teknologi saat ini nyatanya ikut mempengaruhi aktivitas seseorang. Sekarang, para remaja sudah lebih sering bermain permainan digital seperti game mobile di handphone mereka. Game atau permainan merupakan bentuk kegiatan untuk menghibur diri sendiri serta menghilangkan rasa penat selepas melakukan segala aktivitas keseharian. Seiring majunya perkembangan zaman, game atau permainan pun juga ikut mengalami perubahan yang cukup signifikan. Efek dari kemajuan teknologi dan informasi tersebut membuat berbagai macam permainan terus berkembang. Salah satu permainan yang saat ini sedang banyak diminati para generasi muda masa kini yaitu game mobile. Game mobile sendiri ialah salah satu jenis game yang didesain khusus untuk dapat dioperasikan pada mobile devices seperti smartphone dan tablet $P C s$ dan biasanya tersambung melalui jaringan internet

Berdasarkan hal tersebut dapat disimpulkan bahwa game mobile adalah suatu kegiatan yang kompleks dan terdapat sistem, di mana seseorang ataupun pemain dapat terlibat dalam sebuah konflik buatan. Bermain game sendiri pun merupakan bentuk kegiatan untuk menghibur diri senidiri dan menghilangkan rasa jenuh dalam melakukan aktivitas keseharian, sehingga jika dilihat dari tujuan utamanya bermain game seharusnya tidak dapat mengganggu aktivitas keseharian manusia.

\section{Dampak positif dan negatif bermain mobile game}

Saat ini, generasi muda dapat dengan mudah memilih game mobile yang ingin mereka mainkan dengan bebas pada smartphone mereka, kapan saja dan di mana saja. Sehingga, sedikit banyak game tersebut memberikan dampak pada hidup dan diri mereka. Seperti halnya:

1. Dampak Negatif Mobile Game

a. Menimbulkan Adiksi (Kecanduan).

Sebagian besar game game mobile yang beredar sekarang memang sengaja didesain untuk memunculkan rasa kecanduan pada para pemainnya. Semakin seseorang kecanduan pada suatu game mobile, maka secara tidak langsung pun para pembuat game di luar sana semakin diuntungkan karena peningkatan jumlah pemain semakin meningkat. Akan tetapi keuntungan ini justru dapat menghasilkan dampak yang buruk bagi kesehatan serta psikis para pemain game mobile tersebut,

b. Penyimpangan pada hal-hal negatif.

Walaupun jumlah untuk kasus seperti ini tidak terlalu banyak akan tetapi cukup sering kita temukan sebuah kasus pemain game mobile yang berusaha mencuri ID dan juga data dari pemain lain dengan segala macam cara. Lalu mengambil uang di 
dalamnya atau mengambil semua item yang berharga cukup mahal. Pencurian semacam ini tidak hanya sebatas pada pencurian id dan password, tetapi juga pencurian uang. Salah satunya, mencuri uang SPP demi membeli sebuah item yang terdapat dalam game mobile.

c. Berbicara kasar serta kotor.

Perilaku ini sepertinya sudah mulai sering kita lihat pada saat mereka bermain mobile game, lalu entah karena mengalami kekalahan ataupun karena kesal akan sesama player yang sedang bermain, secara sadar dalam kondisi kesalnya tersebut mereka sering melontarkan kata kata kasar dan juga kotor selagi bermain mobile game.

d. Terbengkalainya segala kegiatan di dunia nyata.

Keterikatan pada tenggat waktu penyelesaian misi di mobile game serta keseruan dalam memainkannya sudah seringkali membuat berbagai macam kegiatan terbengkalai. Seperti halnya, waktu saat beribadah, tugas di sekolah, tugas perkuliahan ataupun perkerjaan lainnya seringkali menjadi terbengkalai karena bermain mobile game.

e. Perubahan pola makan dan waktu istirahat.

Perubahan pada waktu istirahat dan pola makan saat ini sudah cukup sering terjadi pada pemain mobile game yang sudah kecanduan karena terlalu sering bermain. Waktu makan pun menjadi tidak teratur dan mereka pada umumnya sering tidur larut ataupun sampai begadang.

f. Menggangu kesehatan.

Duduk dan terus menerus menatap layar smartphone selama berjam-jam jelas saja dapat menimbulkan dampak negatif bagi tubuh serta kesehatan seseorang. Seperti, dapat mengakibatkan kelelahan pada mata. Hal ini diakibatkan karena mereka pada umumnya yang sudah kecanduan menghabiskan waktu rata-rata tujuh jam setiap hari untuk bermain mobile game. Dengan begitu, indikasi bahwa mobile game dapat mengganggu kesehatan individu adalah nyata.

2. Dampak Positif Mobile Game

a. Meningkatkan Kinerja Otak

Bermain game ataupun mobile game secara tidak berlebihan dapat meningkatkan kinerja otak seseorang, dan juga memiliki kapasitas jenuh yang jauh lebih sedikit jika dibandingkan dengan belajar dan juga membaca sebuah buku.

b. Menghilangkan Stres

Hal ini sudah biasa kita dengar ataupun rasakan, Para peneliti di Indiana University mengemukakan bahwa bermain sebuah game ataupun mobile game dapat mengendurkan ketegangan syaraf dan menghilangkan stress.

c. Menjadi fasih dan mengerti dalam berbahassa asing

Seperti yang suda diketahui bahwa mobile game di zaman sekarang ini hamper semuanya menggunakan Bahasa asing yaitu Bahasa inggris, hal ini secara tidak langsung dapat membuat seseorang yang sedang memainkannya secara tidak langsung belajar untuk mengerti Bahasa tersebut, sehingga meningkatkan kemampuan mereka dalam berbahasa asing.

d. Mengenal berbagai teknologi baru

Pemain mobile game yang sudah sangat sering bermain pasti mengetahui bahwa konten konten setiap mobile game pasti disesuaikan dengan keadaan saat ini. Pada dasarnya, game konten konten baru akan muncul ketika sedang terjadi hal hal yang sedang populer. Sebut saja ketika momen natal, maka mobile game dengan berbagai konten mengenai natal akan segera bermunculan di pasaran dengan memuat benda benda ataupun event yang biasa ada pada saat natal. 
e. Meningkatkan kecepatan dalam mengetik

Salah satu contoh lain dampak positif bagi pemain mobile game ialah dapat meningkatkan kecepatan dalam mengetik. Dalam mobile game yang online para pemain biasanya sering berkomunikasi dengan pemain lain dengan cara mengetik kata ataupun kalimat. Maka dengan hal tersebut para pemain pun akan dituntut untuk mengetik secara cepat sekaligus mengendalikan game yang sedang dimainkan. Dengan hal tersebut maka logika pemain dalam berpikir pun juga dapat mengalami perkembangan.

f. Menambah Konsentrasi

Seorang peneliti dari suatu universitas di Inggris menemukan bahwa sesorang yang sering memainkan sebuah mobile game biasanya memiliki daya konsentrasi yang lebih baik bila dibandingkan dengan yang lain

\section{Cara mengatasi dampak kecanduan bermain mobile game}

1. Niat.

Hal yang paling utama dalam rangka mengatasi kecanduan bermain mobile game yang paling utama adalah sebuah niat, sebuah niat yang kuat untuk mengurangi bermain secara berlebihan. Karena dengan niat yang kuat tersebut secara psikologis maka akan mempermudah dalam mengatasi kecanduan dalam bermain.

2. Mencari kesibukan lain.

Mencari kesibukan serta hal hal lain yang positif, seperti contohnya berolahraga, membaca sebuah buku, jalan jalan ataupun sekedar berkumpul dan berbincang bincang bersama teman teman. Sehingga tidak ada waktu luang untuk bermain mobile game.

3. Mengatur jadwal bermain

Mengurangi waktu bermain dengan mulai menentukan kapan waktunya untuk bermain dan kapan tidak, serta diharuskan untuk mematuhi jadwal tersebut. Untuk tahap pertama mungkin bias dengan mengurangi waktu bermain sedikit demi sedikit.

4. Menghitung jumlah uang yang dikeluarkan.

Dengan cara menghitung banyaknya uang yang telah dikeluarkan untuk bermain mobile game dapat membuat seseorang lebih berpikir untuk tidak menghabiskan uangnya dan mulai berfikir untuk mulai menanbung untuk keperluan yang lebih penting.

5. Menolak dengan halus ajakan untuk bermain.

Tidak jarang sesorang menjadi kecanduan dalam bermain mobile game karena ajakan teman temannya sendiri, oleh karena itu hal untuk mencegahnya ialah menolak ajakan mereka dengan sopan dan halus pada saat mereka mengajak untuk bermain.

Hasil dari pembahasan "Kecanduan mobile game pada generasi masa kini" ialah sebuah poster yang berisikan ajakan kepada para pemainnya untuk sedikit demi sedikit mengurangi waktu bermain mereka dan mulai menerapkan bermain dengan aman dan secukupnya. Dengan begitu, maka kehidupan sehari hari akan seimbang dan tidak terganggu serta menjadi berantakan. Alasan kenapa lebih memilih untuk mengurangi waktu bermain daripada berhenti total pada mobile game tersebut ialah karena mobile game tidak sepenuhnya hanya memiliki dampak negatif saja, akan tetapi mobile game juga memiliki dampak positif bagi pemainnya bila digunakan dengan bijak.

\section{Analisis Khalayak}

Segmentasi

Segmentasi dari poster ini para pemain yang sudah kecanduan dalam bermain mobile game. Berikut merupakan rincian segmentasi poster:

1. Geografis dari perancangan poster ini akan ditampilkan serta dilihat oleh para generasi muda masa kini yang mayoritas tinggal dikota-kota besar seperti Ibu kota Jakarta serta kota-kota besar lainnya yang ingin mengajak mereka untuk mengurangi waktu saat bermain mobile game melalui sebuah illustrasi yang ada pada poster. 
2. Demografis

a. Usia yang menajdi target untuk illustrasi poster ini ialah para remaja rentang usia 15-20 Tahun. Yang dimana pada rentang usia tersebut banyak sekali yang kecanduan bermain mobile game

b. Illustrasi poster ini dapat dibaca oleh semua gender.

\section{Proses Pembuatan Poster}

1. Tahapan Mencari Ide atau Konsep

Sebelum ke tahap pembuatan, terjadi tahapan pencarian dan penentuan ide atau konsep menjadi bagian paling awal. Pencarian ide ini dengan research dengan tema yang sesuai dengan pembahasan materi diatas.

a. Membuat desain layout poster

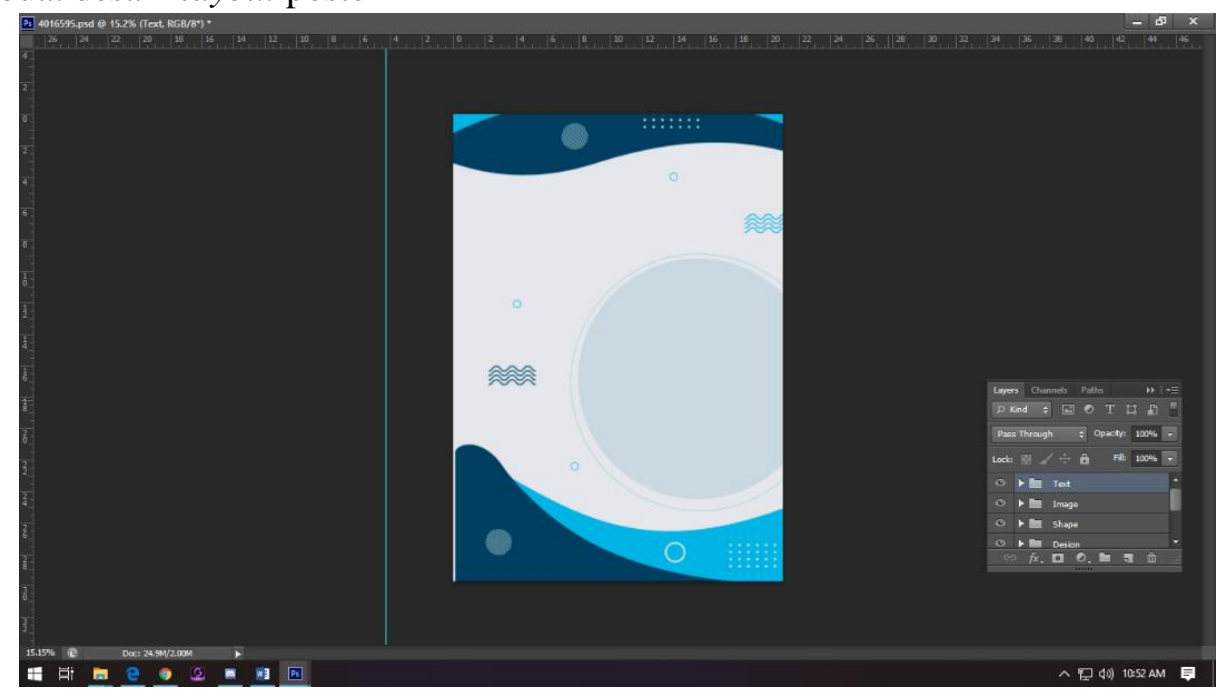

Gambar 1 Desain layout dari poster yang akan dibuat

Sumber: Dokumentasi pribadi

b. Memasukan gambar dua remaja yang sedang bermain bersama

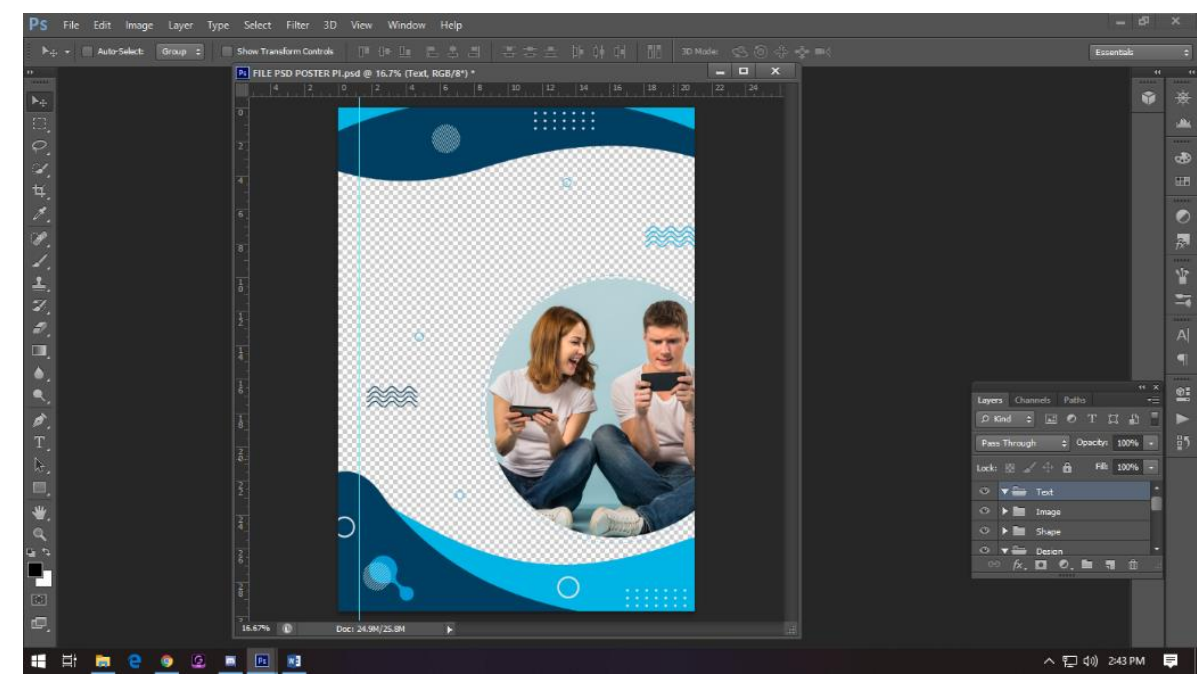

Gambar 2 Dua remaja yang sedang bermain mobile game melalui smartphone-nya Sumber: Dokumentasi pribadi 
c. Penambahan text

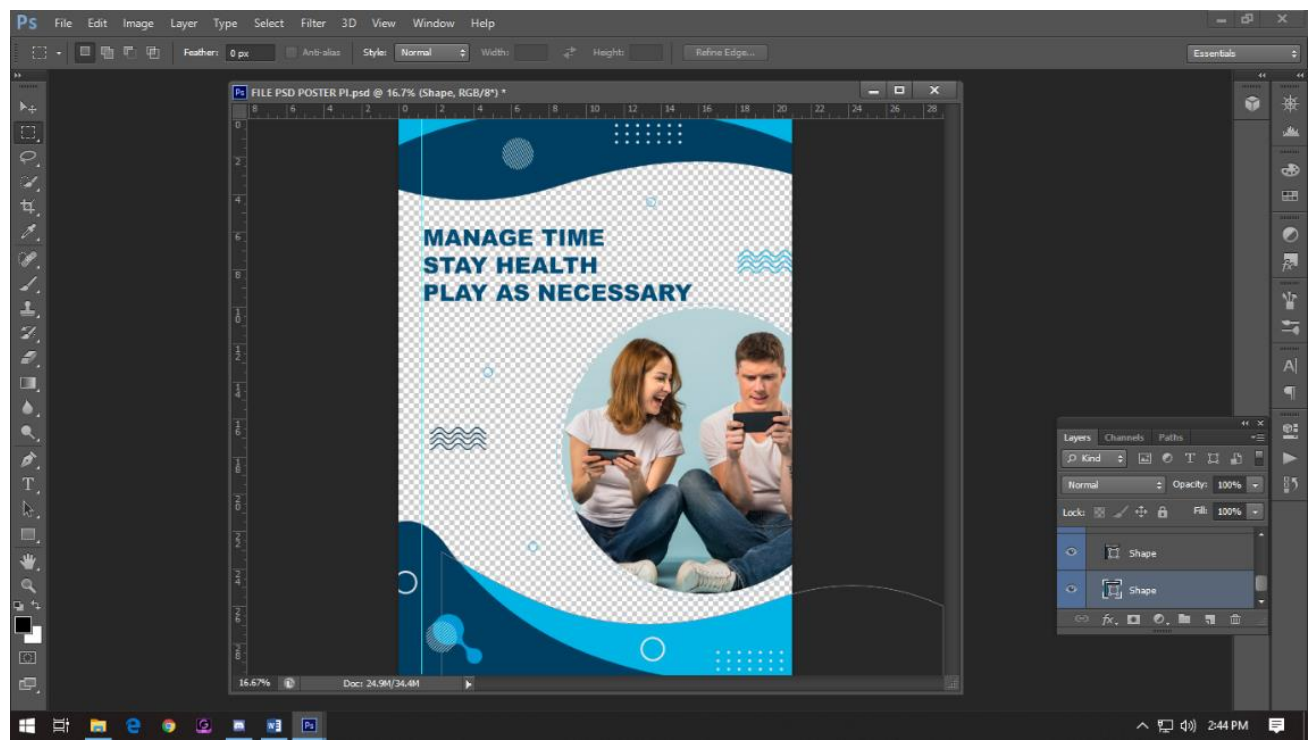

Gambar 3 Menambahkan text "MANAGE TIME STAY HEALTH PLAY AS NECESSARRY".

Sumber: Dokumentasi pribadi

\section{Hasil Perancangan Poster}

Setelah selesai dalam tahap perancangan poster, berikut ini hasil akhir dari poster

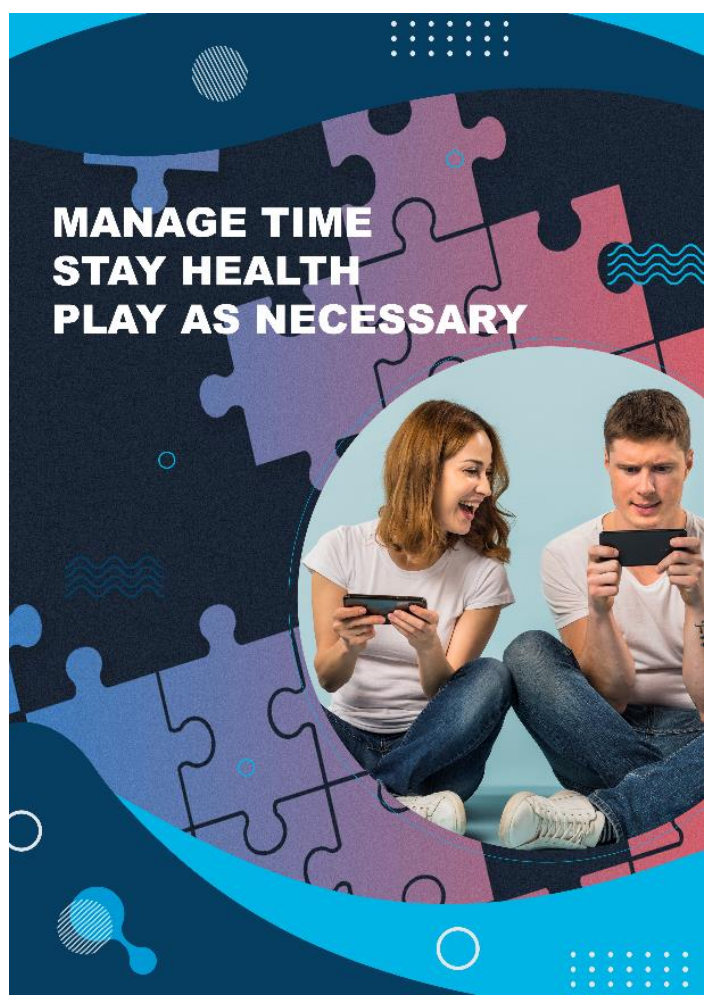

Gambar 4 Poster

Sumber: Dokumen Pribadi 
Pada illustrasi poster terakhir ini dibuat ilustrasi dua orang remaja generasi masa kini yang sedang asyik bermain mobile game di smartphone mereka sebagai salah satu elemen pendukung pada poster ini yang ditujukan bahwa poster ini bertemakan tentang mobile game yang ada di smartphone. Dan juga pada poster ini terdapat Key Message bertuliskan "play safe, play as necessary". "Makna dari key message ini adalah bermainlah mobile game dengan aman dan juga secukupnya sebagai sebuah pengingat bagi para generasi masa kini yang kecanduan bermain mobile game agar senantiasa bermain secukupnya saja dan tidak berlebihan.

Dengan adanya poster ini diharapkan dapat memberikan kesadaran kepada para remaja generasi masa kini, bahwa mengatur waktu dan tetap menjaga kesehatan sangat penting, jangan karena bermain game, para remaja menjadi lupa waktu dan tidak menjaga kesehatan.

\section{SIMPULAN}

Dari pembahasn di atas sudah dapat diambil kesimpulan bahwa Mobile game adalah sebuah permainan yang dimainkan di dalam suatu smartphone baik online maupun offline Perkembangan dari mobile game sendiri tidak pernah lepas dari perkembangan teknologi smartphone dan jaringan internet saat ini. Selain itu Mobile game juga diketahui mempunyai beberapa dampak positif dan negatif bagi pemainnya. Bagi pemain yang dapat menggunakannya dengan bijak dan benar maka dampak positif yang mereka dapatkan dan juga rasakan, namun sebaliknya bagi yang tidak bisa menggunakannya dengan benar akan banyak sekali dampak negatif yang dapat didapat serta dirasakan. Seperti dari segi uang, waktu, semangat belajar, psikologi, kesehatan, dan juga hal sosial. Hal ini ditakutkan dapat menjadi semakin buruk di kemudian hari bila tidak ditangani.

\section{DAFTAR PUSTAKA}

Ulum, B. (2018). Game “Mobile Legends Bang Bang” di kalangan Mahasiswa UIN Sunan Ampel Surabaya dalam tinjauan "One Dimensional Man" Herbert Marcuse (Doctoral dissertation, UIN Sunan Ampel Surabaya).

Febriandari, D., \& Nauli, F. A. (2016). Hubungan kecanduan bermain game online terhadap identitas diri remaja. Jurnal Keperawatan Jiwa, 4(1), 50-56.

Surbakti, K. (2017). Pengaruh Game Online terhadap Remaja. Jurnal Curere, 1(1).

Siswanto, Y., \& Purnama, B. E. (2013). Rancang Bangun Aplikasi Mobile Game Edukasi Ilmu Pengetahuan Alam Untuk Anak Kelas VI Sekolah Dasar. Speed-Sentra Penelitian Engineering dan Edukasi, 5(4).

Ismail, K. A. (2016). Fenomena permainan game online Defense of the Ancients (Dota 2) pada prestasi akademik mahasiswa perguruan tinggi di Kota Malang (Doctoral dissertation, Universitas Islam Negeri Maulana Malik Ibrahim).

Setiawan, H. S. (2018). Analisis Dampak Pengaruh Game Mobile Terhadap Aktifitas Pergaulan Siswa Sdn Tanjung Barat 07 Jakarta. Faktor Exacta, 11(2), 146-157.

Rani, D., Hasibuan, E. J., \& Barus, R. K. I. (2018). Dampak Game Online Mobile Legends: Bang Bang terhadap Mahasiswa. PERSPEKTIF, 7(1), 6-12.

Munandar, U. (2004). Pengembangan Emosi dan Kreativitas. Jakarta: Rineka Cipta.

Fadillah, F. A., \& Iqbal, M. (2019). Poster Kecanduan Game terhadap Anak Usia Dini. Jurnal Desain, 7(1), 38-48. 
Masya, H., \& Candra, D. A. (2016). Faktor-faktor yang mempengaruhi perilaku gangguan kecanduan game online pada peserta didik kelas X di Madrasah Aliyah Al Furqon Prabumulih tahun pelajaran 2015/2016. KONSELI: Jurnal Bimbingan dan Konseling (EJournal), 3(2), 103-118.

Ulfa, M., \& Risdayati, R. (2017). Pengaruh Kecanduan Game Online Terhadap Perilaku Remaja Di Mabes Game Center Jalan Hr. subrantas Kecamatan Tampan Pekanbaru (Doctoral dissertation, Riau University).

Jannah, N., Mudjiran, M., \& Nirwana, H. (2015). Hubungan kecanduan game dengan motivasi belajar siswa dan implikasinya terhadap Bimbingan dan Konseling. Konselor, 4(4), 200207. 